\title{
Extraction and HPLC Analysis of Sage (Salvia officinalis) Plant
}

Fatma Ebru K*, Ayse A and Caglar K

Aksuvital R and D Center, Kavakli Mah, Kuzey Cad, Beylikdüzü, Istanbul, Turkey

*Corresponding author: Fatma Ebru K, Aksuvital R and D Center, Kavakli Mah, Kuzey Cad, Beylikdüzü, İstanbul, Turkey, Tel: +90 2126715547 ; E-mail: e.koc@aksuvital.com.tr

Received: October 05, 2017; Accepted: October 16, 2017; Published: October 20, 2017

Copyright: (c) 2017 Fatma Ebru K, et al. This is an open-access article distributed under the terms of the Creative Commons Attribution License, which permits unrestricted use, distribution, and reproduction in any medium, provided the original author and source are credited.

\begin{abstract}
In this study, the sage (Salvia officinalis) plant collected from the Mediterranean region was extracted with different solvents and methods. The extract yields were compared. The quantities of rosmarinic acid, carnosic acid and carnosol, which are responsible for the antioxidant capacity of the sage plant, were analyzed qualitatively and quantitatively by an HPLC.

Ground sage plant were sieved with 70 mesh sieves. Maceration were done for powder sage plant at $45^{\circ} \mathrm{C}$ with $70 \%$ ethyl alcohol in "1:6" (w/v) ratio at different time $(3 ; 6 ; 8 ; 10$ hours); $100 \%$ methanol and $100 \%$ ethanol extractions; Soxhlet extraction efficiencies were compared. The proportions of rosmarinic acid and the amounts of carnosic acid and carnosol were analyzed in the extracted at UV detector and $280 \mathrm{~nm}$ wavelength by a Thermo Scientific Ulimate HPLC instrument. As a result of the experiments, a maceration method with $70 \%$ ethanol with $25 \%$ extraction yield was chosen. As a result of calculations on the standard graphic of rosmarinic acid in analytical standards. It was determined that $7.45 \mathrm{mg}$ "rosmarinic acid"; $3.42 \mathrm{mg}$ "carnosol+carnosic acid" in gram $70 \%$ ethanol extract of sage.
\end{abstract}

Keywords: HPLC analysis; Salvia officinalis; Rosmarinic acid; Carnosic acid

\section{Introduction}

There are over 700 species within the genus Salvia. Salvia officinalis L., also known as garden sage, culinary sage, or common sage, is the representative species. It is an evergreen perennial shrub native to the Mediterranean region with broad, grayish-green leaves. Major growing regions today include central Europe, Albania, and the United States. Sage can be harvested two or three times a year. Cultivated sage is generally dried using a heated dehydrator [1]. Sage (Salvia officinalis) is a $50-100 \mathrm{~cm}$ high, purplish blue flowering, simple leafy, perennial and bitter plant. It grows on mountain slopes, is widely cultured. 1-2.5\% contains essential oil, tannins and bitter substances. They're very rich in phenols, flavonoids and flavonols. The so-called "apple oil" or "bitter apple oil" is also produced from Anatolian sage. Sage is widely used for cold due to antiinflammatory, antimicrobial effect $[2,3]$.

In the last few decades, intensive studies of sage are about its phenolic antioxidant components. Several studies have shown sage to contain a range of potent antioxidants [4,5]. Due to the essential oil and antioxidant components of sage it is an economically interesting plant to study. Sage antioxidants can be used as an alternative to the well-known rosemary antioxidants for the protection and preservation of certain food and nutraceutical products to extend their shelf life $[6,7]$.

The antioxidant properties have been related to the major marker compounds carnosic acid, carnosol and rosmarinic acid [8,9]. Sage extracts also contain flavonoids and other phenolics which may contribute to the total antioxidant activity. Conventional solvent extraction has been reported in a laboratory scale using acetone, hexane, methanol or ethanol $[10,11]$.

\section{Materials and Methods}

\section{Materials}

The sage was supplied from DOVİT Gida A.Ş. The analytical grade purity solvents purchased from Sigma (St. Louis, MO, USA). The quantities of rosmarinic acid, carnosic acid and carnosol, which are responsible for the antioxidant capacity of the sage plant, were analyzed qualitatively and quantitatively by Thermo Scientific Ultimate HPLC device in the laboratory of Aksuvital R and D Center.

\section{Methods}

Before extractions, the sage leaves were grained by a ball mill and sieved with 70 mesh sieve. Maceration were done for sages at $45^{\circ} \mathrm{C}$ with $70 \%$ ethyl alcohol; $100 \%$ methanol and $100 \%$ ethanol in ratios ("1: 6 " "w/v") and time ( $3 ; 6 ; 8 ; 10$ hours) in a water bath. And also, Soxhlet extraction were done with $100 \%$ ethanol. All extraction efficiencies were compared. After, the proportions of rosmarinic acid and the amounts of carnosic acid and carnosol were analyzed in the extracted at UV detector and $280 \mathrm{~nm}$ wavelength Thermo Scientific-Dionex Ultimate 3000 HPLC; colon: Acclaim C18, $3 \mu \mathrm{m}, 120$ Ao $(4.6 \mathrm{~mm} \times$ $150 \mathrm{~mm}$ ); mobile phase: (30:70) Asetonitril:Su, Asetonitril (2.5), formik asit (0.5); flow rate : $0.2 \mathrm{ml} \backslash$ dak; $\mathrm{pH} 2.4$ thampon.

\section{Results and Discussion}

A systematic comparison of the parameters extraction method, extraction time, solvent composition, major bioactives (rosmarinic acid and "carnosic acid+carnosol") amount were carried out in laboratory scale. 


\section{Effect of extraction method, extraction time and solvent composition}

As results of the experiments, maximum extract yield was obtained $36.72 \%$ with methanol $100 \%$ maceration method. Soxhlet and other maceration methods extract yields were the proximate same at the same extraction time (Figures 1 and 2).

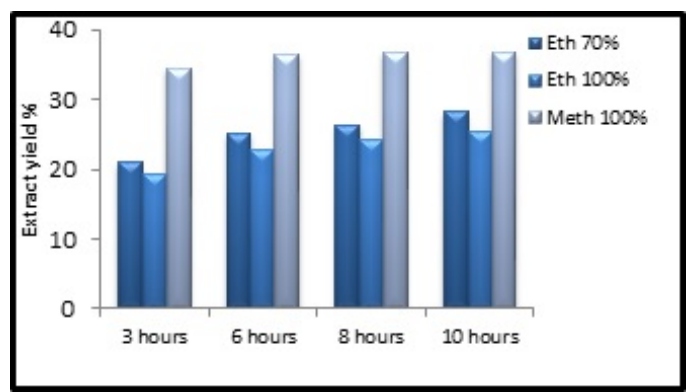

Figure 1: Change of extract yield (\%) for maceration.

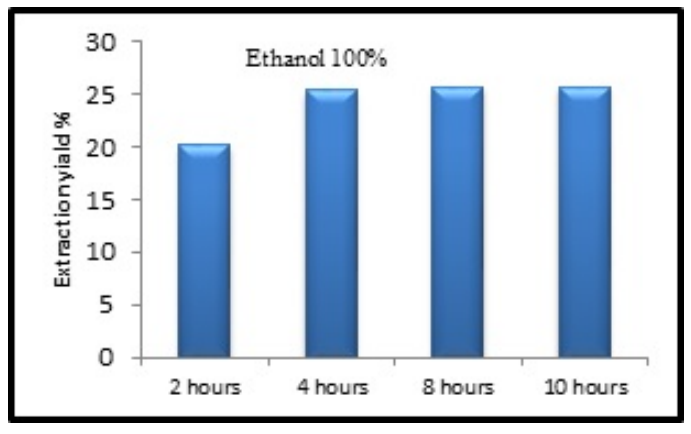

Figure 2: Change of extract yield (\%) for soxhlet.

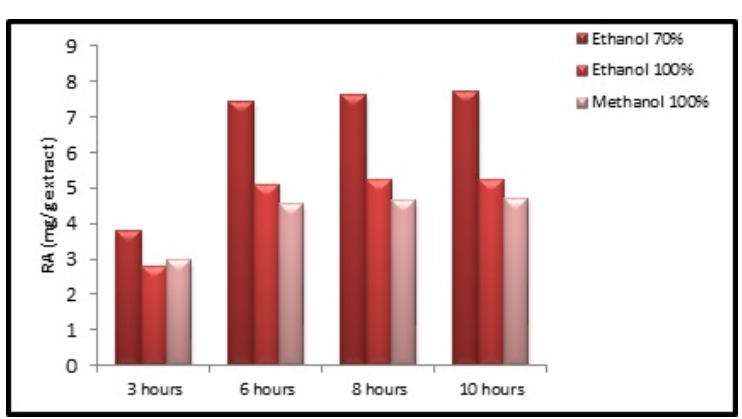

Figure 3: Change of Rosmarinic acid amount (mg/gext.) for maceration method.

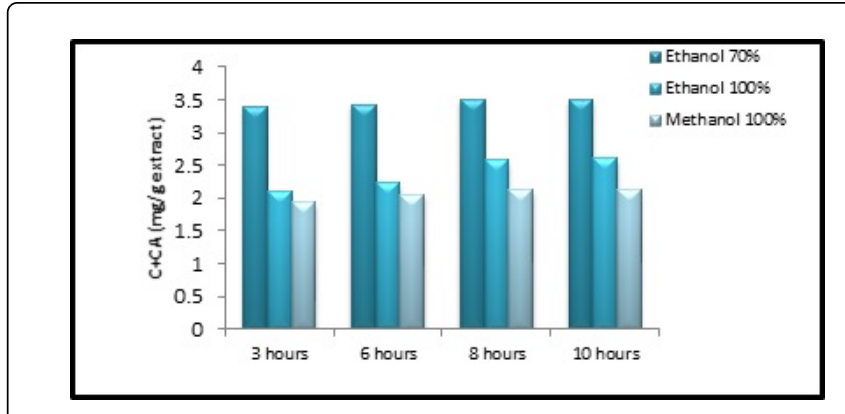

Figure 4: Change of "Carnosol+Carnosic acid" (mg/g ext.) for maceration method.

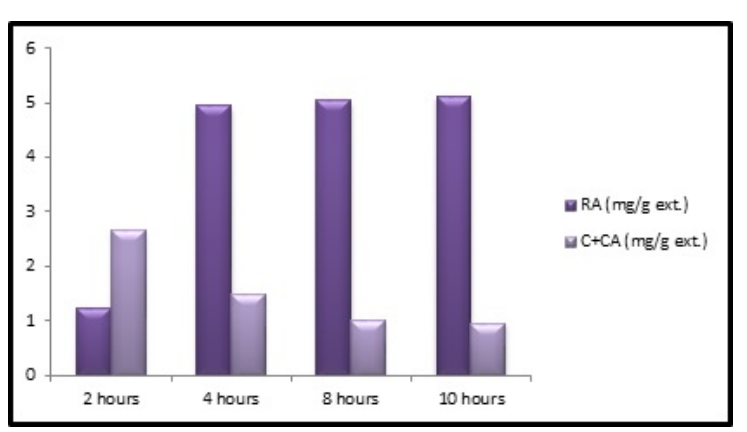

Figure 5: Change of RA and "C+CA" (mg/g ext.) for soxhlet method.

The extract yield and bioactives (Rosmarinic acid and carnosol+ carnosic acid) amounts are a function of the extraction time. As the extraction time was increased the extract yield and bioactives amounts. Since rosmarinic acid (RA) maximum value $7.42 \mathrm{mg} / \mathrm{g}$ ext. were obtained for maceration method ethanol 70\% (Figure 3). "C+CA" were the major phenolics in sage, they were $3.45 \mathrm{mg} / \mathrm{g}$ ext. for same method (Figures 4 and 5). But these compounds were degraded at longer extraction times and higher extraction temperature (Soxhlet ext.). It is suggested that extraction time of no longer than 3-6 h and extraction temperature of no higher $50^{\circ} \mathrm{C}$ (maceration ext.).

\section{Conclusion}

The aim of this work was to study the extract efficiency of three major bioactive compounds in sage: rosmarinic acid, carnosic acid and carnosol. As a function of the process conditions: extraction methods, extraction temperature, extraction time and solvent composition.

The optimal extraction conditions that satisfied were found to be at an extraction temperature of $40-50^{\circ} \mathrm{C}$, an extraction time of $3-6 \mathrm{~h}$, solvent-to-sage ratio of $6: 1$ and $70-80 \mathrm{wt} \%$ ethanol for maceration method. Rosmarinic acid was found to be stable under all process conditions. Carnosol and carnosic acid were found to degrade rapidly at longer extraction time and higher extraction tempereture. When a blend of carnosic acid, carnosol, and rosmarinic acid could be subjected to the various process conditions, carnosol may be found to be relatively stable. Our future studies would be tried to obtain more stable blend. Extraction yield results were found to be in good at a laboratory scale. These datas can be used for that the optimised process can be carried out at an industrial scale. 
Citation: Fatma Ebru K, Ayse A, Caglar K (2017) Extraction and HPLC Analysis of Sage (Salvia officinalis) Plant. Nat Prod Chem Res 5: 298.

\section{Acknowledgment}

This work was supported by The Scientific and Technological Research Council of Turkey (TUBITAK).

\section{References}

1. Rao LJ, Singh M, Raghavan B, Abraham KO (1998) Rosemary (Rosmarinus officinalis L.): Impact of drying on its flavor quality. J Food Quality 21: 107-115.

2. Monografları F, Tedavide Kullanılan B, Medikal MN (2010) Assessment report on Rosmarinus officinalis L., aetheroleum and Rosmarinus officinalis L., folium.

3. Koşar M, Göger F, Başer KHC (2011) In vitro antioxidant properties and phenolic composition of Salvia halophila Hedge from Turkey. Food Chem 129: 374-379.

4. Bisio A, Romussi G, Ciarallo G, De Tommasi N (1997) Flavonoide und triterpenoide aus Salvia blepharophylla Brandegee ex Epling. Pharmazie 52: 330-331.
5. Wang M, Li J, Rangarajan M, Shao Y, LaVoie EJ, et al. (1998) Antioxidative phenolic compounds from sage (Salvia officinalis). J Agricul Food Chem 46: 4869-4873.

6. Kimura Y, Kanamori T (1982) US Patent No. 4,363,823. Washington, DC: U.S. Patent and Trademark Office.

7. Wellwood CR, Cole RA (2004) Relevance of carnosic acid concentrations to the selection of rosemary, Rosmarinus officinalis (L.), accessions for optimization of antioxidant yield. J Agricul Food Chem 52: 6101-6107.

8. Chang SS, OstricMatijasevic B, Hsieh OA, Huang CL (1977) Natural antioxidants from rosemary and sage. J Food Sci 42: 1102-1106.

9. Cuvelier ME, Richard H, Berset C (1996) Antioxidative activity and phenolic composition of pilot-plant and commercial extracts of sage and rosemary. J Ameri Oil Chem Soc 73: 645-652.

10. Areias F, Valentão P, Andrade PB, Ferreres F, Seabra RM (2000) Flavonoids and phenolic acids of sage: influence of some agricultural factors. J Agricul Food Chem 48: 6081-6084.

11. Koşar M, Dorman HJD, Hiltunen R (2005) Effect of an acid treatment on the phytochemical and antioxidant characteristics of extracts from selected Lamiaceae species. Food Chem 91: 525-533. 